\title{
BMJ
}

\section{Prostate specific antigen for early detection of prostate cancer: longitudinal study}

\author{
Benny Holmström, urologist, ${ }^{1,2}$ Mattias Johansson, postdoctoral fellow, ${ }^{2,3}$ Anders Bergh, professor of \\ pathology, ${ }^{4}$ Ulf-Håkan Stenman, professor of clinical chemistry, ${ }^{5}$ Göran Hallmans, professor of nutritional \\ research, ${ }^{6}$ Pär Stattin, professor of urology ${ }^{2}$
}

${ }^{1}$ Department of Surgery, Gävle Hospital, S-801 87 Gävle, Sweden

${ }^{2}$ Department of Surgical and Perioperative Sciences, Urology and Andrology, Umeå University, S-901 85 Umeå, Sweden

${ }^{3}$ International Agency for Research on Cancer (IARC), 150 cours Albert Thomas, 69008 Lyon, France

${ }^{4}$ Department of Medical Biosciences, Pathology, Umeå University

${ }^{5}$ Department of Clinical Chemistry, Helsinki University Central Hospital, Biomedicum, POB 700, FIN-00029 HUS, Finland

${ }^{6}$ Department of Public Health and Clinical Medicine, Nutritional Research, Umeå University

Correspondence to: M Johansson, Genetic Epidemiology Group (GEP), International Agency for Research on Cancer (IARC), 150 cours Albert Thomas, 69008 Lyon, France JohanssonM@fellows.iarc.fr

Cite this as: BMJ 2009;339:b3537 doi:10.1136/bmj.b3537

\section{ABSTRACT}

Objective To evaluate if prostate specific antigen test attains validity standards required for screening in view of recent prostate cancer screening trial results.

Design Case-control study nested in longitudinal cohort. Setting Västerbotten Intervention Project cohort, Umeå, Sweden.

Participants 540 cases and 1034 controls matched for age and date of blood draw.

Main outcome measure Validity of prostate specific antigen for prediction of subsequent prostate cancer diagnosis by record linkage to cancer registry.

Results Blood samples were drawn on average 7.1 (SD 3.7) years before diagnosis. The area under the curve for prostate specific antigen was 0.84 (95\% confidence interval 0.82 to 0.86 ). At prostate specific antigen cut-off values of 3, 4, and $5 \mathrm{ng} / \mathrm{ml}$, sensitivity estimates were $59 \%, 44 \%$, and $33 \%$, and specificity estimates were $87 \%$, $92 \%$, and $95 \%$. The positive likelihood ratio commonly considered to "rule in disease" is 10 ; in this study the positive likelihood ratios were 4.5, 5.5, and 6.4 for prostate specific antigen cut-off values of 3,4 , and $5 \mathrm{ng} /$ $\mathrm{ml}$. The negative likelihood ratio commonly considered to "rule out disease" is 0.1 ; in this study the negative likelihood ratios were $0.47,0.61$, and 0.70 for prostate specific antigen cut-off values of 3, 4, and $5 \mathrm{ng} / \mathrm{ml}$. For a cut-off of $1.0 \mathrm{ng} / \mathrm{ml}$, the negative likelihood ratio was 0.08 .

Conclusions No single cut-off value for prostate specific antigen concentration attained likelihood ratios formally required for a screening test. Prostate specific antigen concentrations below $1.0 \mathrm{ng} / \mathrm{ml}$ virtually ruled out a prostate cancer diagnosis during the follow-up. Additional biomarkers for early detection of prostate cancer are needed before population based screening for prostate cancer should be introduced.

\section{INTRODUCTION}

Serum concentrations of prostate specific antigen have been widely used for early detection of prostate cancer, ${ }^{1-3}$ and prostate specific antigen has been described as the best circulating tumour marker in oncology. ${ }^{4-6}$ Recently, the European Randomized Study of Screening for Prostate Cancer (ERSPC) reported a $20 \%$ decrease in the rate of death from prostate cancer in the screening arm; however, considerable overdiagnosis and overtreatment occurred in the screening arm, as 1068 men had to be screened and 48 men had to have curative treatment in order to save one man's life. ${ }^{7}$ These data highlight the need for a rigorous examination of the validity of prostate specific antigen as a screening test for prostate cancer.

Cross sectional studies have shown that approximately $10 \%$ of middle aged men have prostate specific antigen concentrations above $4 \mathrm{ng} / \mathrm{ml}$ and approximately a quarter of these men have prostate cancer on biopsy. ${ }^{89}$ Studies of this design can provide accurate data on the positive predictive value of prostate specific antigen for diagnosis of prostate cancer, as men with high prostate specific antigen concentrations have biopsy for verification of the diagnosis. These studies can also provide relatively accurate estimates of specificity given that prostate cancer is relatively rare among men with low prostate specific antigen concentrations. ${ }^{10-12}$ However, in cross sectional studies, cancer status is not verified in men with prostate specific antigen concentrations below the threshold for biopsy, so such studies cannot provide accurate estimates of sensitivity. Estimates of sensitivity are necessary for calculation of likelihood ratios, ${ }^{13}$ which describe the likelihood that a given test result would be expected in a person with a disease compared with the likelihood that the same result would be expected in a person without the disease. A positive likelihood ratio above 10 for a diagnostic test is considered to be a strong evidence to "rule in" disease, whereas a negative likelihood ratio below 0.1 is considered sufficient evidence to "rule out" disease. ${ }^{14}$ Importantly, likelihood ratios are not affected by the prevalence of the disease ${ }^{13}$; likelihood ratios are, therefore, powerful tools for evaluating biomarkers.

Sensitivity, specificity, and likelihood ratios can be calculated only when case status is known for all participants in a study. Case status is known both in studies in which all men have biopsy regardless of prostate specific antigen concentration and in longitudinal cohort studies in which prostate specific antigen is 
measured in cases identified by subsequent linkage to a cancer registry and in matched controls. ${ }^{15-21}$

The aim of this study was to evaluate prostate specific antigen as a screening test by calculating the sensitivity, specificity, and likelihood ratios of prostate specific antigen concentrations in predicting subsequent diagnosis of prostate cancer in a case-control study nested in a longitudinal cohort.

\section{METHODS}

\section{Study population}

The Västerbotten Intervention Project is an ongoing long term population based cohort study in which all residents in Västerbotten County are invited to a health examination at the age of 40,50, and 60 years. ${ }^{22}$ The health examination includes measurement of height, weight, and blood pressure, as well as a blood draw. Blood is fractioned into plasma, buffy coat, and erythrocyte aliquots and cryopreserved at $-80^{\circ} \mathrm{C}$. By December 2005, the Västerbotten Intervention Project comprised 37031 men who had had a health examination and blood draw. The participation rate was 57\%, and comparison of participants with non-participants in the study has shown relatively small differences in social characteristics and overall health status. ${ }^{23}$

In January 2006 we linked the Västerbotten Intervention Project cohort to the regional cancer registry and identified 654 incident cases of prostate cancer. Of these cases, $540(83 \%)$ men had a prospectively collected blood sample available for biochemical analysis for this study. Clinical characteristics of tumours, including local stage, lymph node stage, metastasis at bone scan, tumour differentiation, and serum prostate specific antigen concentration at the time of diagnosis came from the Northern Sweden part of the National Prostate Cancer Register. ${ }^{24}$ We re-evaluated core biopsies in accordance with Gleason and measured the length of the core biopsies and cancer tissue in the cores. We defined high risk prostate cancer as local tumour stage T3 or T4, Gleason score 8 or higher, World Health Organization grade III (WHO grading was assessed on fine needle aspirate done in 64 men), or presence of lymph node metastasis, bone metastasis, or serum prostate specific antigen concentrations above $20 \mathrm{ng} / \mathrm{ml}$. No formal screening programme for prostate cancer has been or is in operation in the source population.

As the Västerbotten Intervention Project participants are recruited at even decades, $98 \%$ of our study group consisted of three age clusters: one cluster of men aged 39-40 $(n=16)$ at the time of blood draw, one cluster of men aged 49-50 ( $\mathrm{n}=129)$, and one cluster of men aged 59-60 $(\mathrm{n}=386)$. To keep the large cluster intact in subgroup analyses, we divided the participants into one group younger than 59 years at recruitment ( $\mathrm{n}=148$ cases) and one group aged 59 or older at recruitment ( $\mathrm{n}=392$ cases). For each case, we randomly selected two controls (1.9 on average; 1034 in total) who were alive and free of cancer at the time of diagnosis for the index case, within sets matched to the index case for age (six months younger or older than

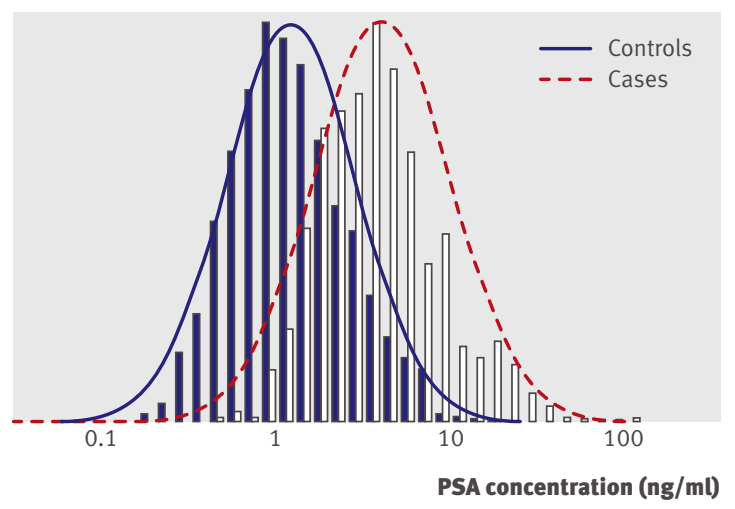

Fig 1| Distribution of plasma prostate specific antigen (PSA) concentrations in cases and controls. Curves indicate frequency functions of calculated normal distribution of logarithm of PSA concentrations according to mean and standard deviation in cases and controls. Histogram shows observed distribution of logarithm of PSA concentrations in cases and controls

the index case) and date of recruitment (within two months before or after blood draw of the index case). All participants gave written informed consent at the time of recruitment.

\section{Biochemical analysis}

Baseline plasma prostate specific antigen concentrations were determined with Wallac Delfia assays (AutoDelfia, Wallac Oy, Turku, Finland) at the Department of Clinical Chemistry, Helsinki University Central Hospital, Helsinki, Finland. Cases and their matched controls were analysed in the same batch, and laboratory personnel were blinded to casecontrol status. At prostate specific antigen concentrations between 0.2 and $100 \mathrm{ng} / \mathrm{ml}$, the intra-assay and inter-assay coefficients of variation were in the range $2-4 \%$. Serum prostate specific antigen concentrations in blood drawn shortly before the diagnostic biopsies had been determined with either Hybritech Tandem-R (Hybritech Inc, San Diego, CA) or the IMx prostate specific antigen assay (Abbot Laboratories, Abbot Park, IL), and values had been recorded in the National Prostate Cancer Register. The coefficient of correlation between the two assays was 0.990 (IMx value= $(1.22 \times$ Tandem value $)-2.80) .{ }^{25}$

\section{Statistical methods}

We used conditional logistic regression to calculate odds ratios for diagnosis of prostate cancer. We calculated specificity and sensitivity for a series of prostate specific antigen cut-off values and estimated the area under the curve in receiver operating characteristics curves for the full study group and for subgroups stratified according to low/high risk cancer, age at blood draw ( $<59$ years and $\geq 59$ years), and time from blood draw to diagnosis. We calculated the positive likelihood ratio as sensitivity/(1-specificity) and the negative likelihood ratio as (1-sensitivity)/specificity. We used the positive and negative likelihood ratios to estimate the probability of diagnosis of prostate cancer 
during follow-up given the information of the prostate specific antigen concentration (post-test probability), assuming a baseline probability of diagnosis of prostate cancer during follow-up of $10 \% .{ }^{1326}$ We used SAS 9.1 for statistical analyses.

\section{RESULTS}

The median plasma concentration of prostate specific antigen was 3.6 (interquartile range $2.2-6.2$ ) $\mathrm{ng} / \mathrm{ml}$ among cases and $1.1(0.7-2.0) \mathrm{ng} / \mathrm{ml}$ in controls. The mean time from the date of blood draw to the date of diagnosis was 7.1 (SD 3.7) years. The median age at baseline was 57.7 (5.4) years in both cases and controls. Age at date of blood draw among controls was positively correlated with prostate specific antigen concentrations $(r=0.23, \quad \mathrm{P}<0.001)$. Figure 1 shows the distribution of prostate specific antigen concentrations in cases and controls.

Table 1 shows the characteristics of the tumours. At the time of diagnosis, $445(86 \%)$ cases had a clinical local stage T1 or T2 tumour. Prostate specific antigen concentrations at diagnosis were higher than $10 \mathrm{ng} / \mathrm{ml}$ in $285(56 \%)$ men, $187(35 \%)$ cases had a tumour differentiation Gleason score of 7 or higher or WHO grade III, and $41(12 \%)$ cases had bone metastasis. Investigations were started after prostate specific antigen testing at a health check-up in $118(23 \%)$ men and for symptoms or other causes in 391 (77\%) men. High risk prostate cancer was present in $185(34 \%)$ cases.

Compared with a reference group of men with prostate specific antigen concentrations below $1 \mathrm{ng} / \mathrm{ml}$, men with concentrations between 1 and $2 \mathrm{ng} / \mathrm{ml}$ had an odds ratio of diagnosis of prostate cancer during follow-up of 9.1 (95\% confidence interval 5.0 to 16.5). For men with prostate specific antigen concentrations between 2 and $3 \mathrm{ng} / \mathrm{ml}$, the odds ratio was 23.3 (12.3 to 43.9); for those with concentrations between 3 and 4 $\mathrm{ng} / \mathrm{ml}$, the odds ratio was 43.9 (22.1 to 87.3 ); for those with concentrations between 4 and $10 \mathrm{ng} / \mathrm{ml}$, the odds ratio was 68.1 (35.2 to 130.6); and for men with prostate specific antigen concentrations above $10 \mathrm{ng} / \mathrm{ml}$, the odds ratio was 239.5 (89.3 to 642.3 ).

Validity of prostate specific antigen in predicting subsequent prostate cancer diagnosis during follow-up In the full group, the area under the curve for prostate specific antigen was 0.84 (95\% confidence interval 0.82 to 0.86$)$. It was higher for cases with a short lag time than for those with a long lag time, higher among cases aged under 59 at the time of recruitment than in those over 59, and higher for high risk tumours than for low risk tumours (table 2).

Table 3 shows estimates of sensitivity, specificity, likelihood ratio, and post-test probability. The sensitivity was $44 \%$ and the specificity $92 \%$ when we used a prostate specific antigen cut-off of $4.0 \mathrm{ng} / \mathrm{ml}$ in the full study group. When we decreased the cut-off to $3.0 \mathrm{ng} / \mathrm{ml}$, the sensitivity increased to $59 \%$ and the specificity decreased to $87 \%$. With a prostate specific antigen cut-off of $4.0 \mathrm{ng} / \mathrm{ml}$, the positive and negative likelihood ratios were 5.45 and 0.61 ; with a prostate

\section{Table 1|Characteristics of cases and tumours}

Continuous varia

Age at diagnosis (years)

Time between blood draw and diagnosis (years)

Prostate specific antigen at diagnosis $(\mathrm{ng} / \mathrm{ml})$

Prostate specific antigen at blood draw $(\mathrm{ng} / \mathrm{ml})$

Fraction of malignant tissue in biopsy (\%)

Discrete variables-No (\%)

Mode of diagnosis:

Health check-up

Symptoms, other reasons

Missing

391 (76.8)

Stage:

T1a, b

31

\begin{tabular}{lc} 
T1a, b & $24(4.7)$ \\
\hline T1c & $244(47.4)$ \\
\hline T2 & $177(34.4)$ \\
\hline T3 & $64(12.4)$ \\
\hline T4 & $6(1.2)$ \\
\hline TX & 25 \\
\hline Lymph node metastasis:
\end{tabular}

\begin{tabular}{cc}
\hline N0 & $164(92.1)$ \\
\hline N1 & $14(7.9)$ \\
\hline NX & 362 \\
\hline
\end{tabular}

Bone metastasis:

\begin{tabular}{cc}
\hline M0 & $315(88.5)$ \\
\hline M1 & $41(11.5)$ \\
\hline MX & 184 \\
\hline Gleason score: &
\end{tabular}

\begin{tabular}{lc}
\hline $2-6$ & $295(63.0)$ \\
\hline 7 & $130(27.8)$ \\
\hline $8-10$ & $43(9.2)$ \\
\hline Missing & 72
\end{tabular}

WHO grade where Gleason score missing:

\begin{tabular}{lc}
\hline I & $25(39.1)$ \\
\hline III & $25(39.1)$ \\
\hline Missing & $14(21.9)$ \\
\hline Prostate specific antigen at diagnosis $(\mathrm{ng} / \mathrm{ml}):$ & 8 \\
\hline $0-4$ & $24(4.7)$ \\
\hline $4-10$ & $204(39.8)$ \\
\hline $10-20$ & $147(28.7)$ \\
\hline $20-50$ & $75(14.6)$ \\
\hline $50-100$ & $29(5.7)$ \\
\hline$\geq 100$ & $34(6.6)$ \\
\hline Missing & 27 \\
\hline High/low risk cancer*: & $355(65.7)$ \\
\hline Low risk & $185(34.3)$ \\
\hline High risk
\end{tabular}

*High risk defined as clinical local tumour stage T3 or T4, lymph node metastasis (N1), bone metastasis (M1), Gleason score $\geq 8$, WHO grade III, or serum levels of prostate specific antigen at diagnosis $>20 \mathrm{ng} / \mathrm{ml}$; low risk defined as absence of all of these factors.

specific antigen cut-off of $3.0 \mathrm{ng} / \mathrm{ml}$ the positive and negative likelihood ratios were 4.51 and 0.47 . Among 483 men with prostate specific antigen concentrations below $1.0 \mathrm{ng} / \mathrm{ml}, 19(3.9 \%)$ were diagnosed as having prostate cancer. The negative likelihood ratio for a 
Table 2 |Area under curve for categories of cases

\begin{tabular}{|c|c|c|}
\hline Study group & No (cases) & Area under curve $(95 \% \mathrm{Cl})$ \\
\hline Full study group & 540 & 0.84 (0.82 to 0.86$)$ \\
\hline \multicolumn{3}{|c|}{ High/low risk cancer*: } \\
\hline Low risk & 355 & $0.83(0.80$ to 0.85$)$ \\
\hline High risk & 185 & 0.88 (0.85 to 0.91$)$ \\
\hline \multicolumn{3}{|c|}{ Age at blood drawt: } \\
\hline$<59$ years & 148 & $0.87(0.84$ to 0.91$)$ \\
\hline$\geq 59$ years & 392 & $0.84(0.82$ to 0.87$)$ \\
\hline \multicolumn{3}{|l|}{ Lag timef: } \\
\hline$<2$ years & 33 & $0.95(0.92$ to 0.98$)$ \\
\hline$>10$ years & 109 & $0.76(0.72$ to 0.80$)$ \\
\hline$\ll 4$ years & 138 & $0.92(0.90$ to 0.94$)$ \\
\hline$\geq 4$ years & 402 & $0.82(0.80$ to 0.84$)$ \\
\hline \multicolumn{3}{|c|}{$\begin{array}{l}\text { *High risk defined as clinical local tumour stage T3 or T4, lymph node } \\
\text { metastasis (N1), bone metastasis (M1), Gleason score } \geq 8 \text {, WHO grade III, } \\
\text { or serum levels of prostate specific antigen at diagnosis }>20 \mathrm{ng} / \mathrm{ml} \text {; low } \\
\text { risk defined as absence of all of these factors. } \\
\text { †Same as age at recruitment. } \\
\text { †Time from blood draw to diagnosis. }\end{array}$} \\
\hline
\end{tabular}

prostate specific antigen cut-off of $1.0 \mathrm{ng} / \mathrm{ml}$ was 0.08 . Six $(1.2 \%)$ cases with prostate specific antigen concentrations below $1.0 \mathrm{ng} / \mathrm{ml}$ were diagnosed as having high risk prostate cancer, and for those men the time between blood draw and diagnosis was between five and 13 years.

Using the positive and negative likelihood ratio estimates, assuming a baseline risk of $10 \%$ of diagnosis of prostate cancer during the follow-up, we estimated the probability of diagnosis of prostate cancer (post-test $\mathrm{P}$ ) for a man with a prostate specific antigen concentration above $4.0 \mathrm{ng} / \mathrm{ml}$ to be 0.38 and that for a man with a concentration below $4.0 \mathrm{ng} / \mathrm{ml}$ to be 0.06 . The corresponding post-test probability for prostate cancer with a prostate specific antigen concentration above $1.0 \mathrm{ng} /$ $\mathrm{ml}$ was 0.16 , and that for a concentration below $1.0 \mathrm{ng} /$ $\mathrm{ml}$ was 0.01 . Figure 2 shows a Fagan's nomogram illustrating post-test probabilities. ${ }^{27}$

\section{DISCUSSION}

In this longitudinal study, the distribution of prostate specific antigen concentrations in cases and controls largely overlapped. No cut-off value for prostate specific antigen concentrations resulted in positive and negative likelihood ratios required for a screening test.

\section{Prostate specific antigen based screening}

The European Randomized Study of Screening for Prostate Cancer (ERSPC) recently showed that screening and early intervention can reduce the rate of death from prostate cancer but at the cost of considerable overdiagnosis and overtreatment. ${ }^{7}$ The Prostate, Lung, Colorectal, and Ovarian (PLCO) Cancer Screening Trial found no significant difference in the rate of death from prostate cancer between the screening group and the control group. ${ }^{28}$ However, the PLCO result probably reflects contamination among controls of whom a large proportion had been tested for prostate specific antigen.

\section{Best available biomarker for cancer}

In comparison with other putative biomarkers, prostate specific antigen confers extremely high odds ratios even for modestly raised concentrations, ${ }^{2930}$ and our estimates of sensitivity, specificity, and area under the curve were largely similar to results obtained in previous studies with the same longitudinal study design, despite relatively large differences in age at recruitment, lag time, and characteristics of the tumours. ${ }^{16-21}$ These results confirm that circulating prostate specific antigen is a robust marker with a relatively high valid ity in predicting a future diagnosis of prostate cancer.

However, when screening a population with a relatively low prevalence of prostate cancer, extremely high validity must be achieved. In particular, the specificity should exceed $95 \%$ to avoid unnecessary, potentially harmful and costly follow-up procedures in a large number of healthy people. ${ }^{3132}$ In our study, a prostate specific antigen cut-off value of $5.0 \mathrm{ng} / \mathrm{ml}$ was needed to achieve a specificity of $95 \%$, a cut-off resulting in a sensitivity of merely $33 \%$. The difficulties in finding a prostate specific antigen cut-off value resulting in a sufficiently high specificity concurrently with a reasonably high sensitivity (that is, above 50\%) are graphically illustrated in figure 1 by the large overlap in the distribution of prostate specific antigen concentrations in cases and controls.

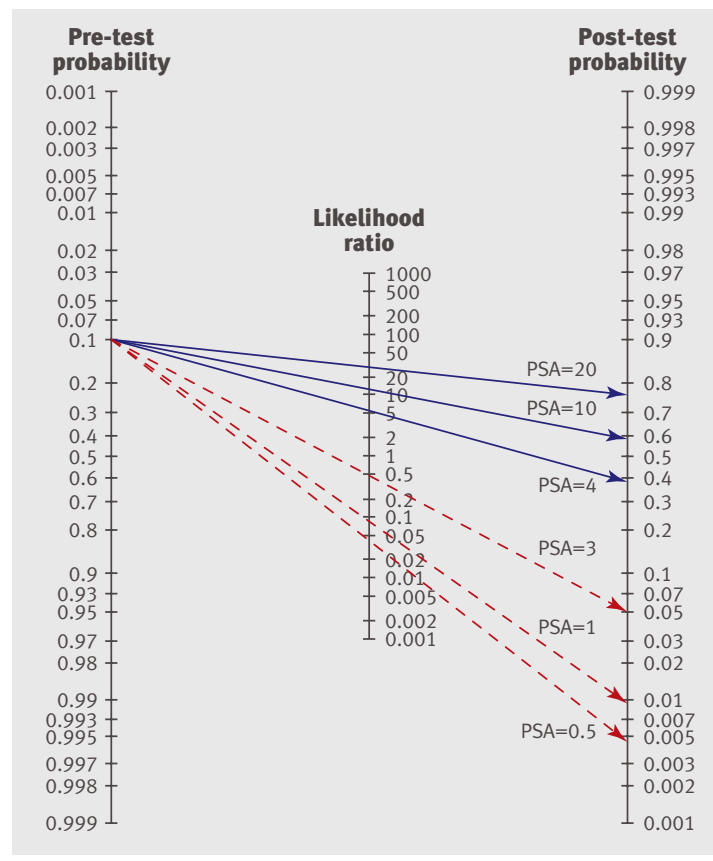

Fig 2 | Fagan's nomogram for calculation of post-test probabilities. Blue (solid) arrows indicate post-test probability of diagnosis during follow-up for men with prostate specific antigen (PSA) concentrations above given cut-offs. Red (broken) arrows indicate post-test probability of diagnosis during follow-up for men with PSA concentrations below given cut-offs 
Table 3 |Validity of prostate specific antigen (PSA) for prediction of subsequent prostate cancer diagnosis

\begin{tabular}{|c|c|c|c|c|c|c|}
\hline PSA cut-off & Sensitivity* & $\begin{array}{c}\text { Positive } \\
\text { likelihood ratio† }\end{array}$ & $\begin{array}{c}\text { Positive } \\
\text { post-test P }\end{array}$ & Specificity§ & $\begin{array}{c}\text { Negative } \\
\text { likelihood ration }\end{array}$ & $\begin{array}{c}\text { Negative } \\
\text { post-test } P^{\star \star *}\end{array}$ \\
\hline 0.5 & 0.99 & 1.15 & 0.11 & 0.13 & 0.04 & 0.005 \\
\hline 1 & 0.96 & 1.73 & 0.16 & 0.44 & 0.08 & 0.01 \\
\hline 2 & 0.78 & 3.15 & 0.26 & 0.75 & 0.30 & 0.03 \\
\hline 3 & 0.59 & 4.51 & 0.33 & 0.87 & 0.47 & 0.05 \\
\hline 4 & 0.44 & 5.45 & 0.38 & 0.92 & 0.61 & 0.06 \\
\hline 5 & 0.33 & 6.35 & 0.41 & 0.95 & 0.70 & 0.07 \\
\hline 10 & 0.13 & 12.34 & 0.58 & 0.99 & 0.88 & 0.09 \\
\hline 20 & 0.05 & 28.11 & 0.76 & 1.00 & 0.95 & 0.10 \\
\hline
\end{tabular}

*Proportion of cases above PSA cut-off.

†Calculated as sensitivity/(1-specificity).

†Probability of prostate cancer diagnosis during follow-up given PSA concentrations above cut-off.

§Proportion of controls below PSA cut-off.

ףCalculated as (1-sensitivity)/specificity.

**Probability of prostate cancer diagnosis during follow-up given PSA concentrations below cut-off.

\section{Likelihood ratios}

Estimates of likelihood ratios are powerful tools in evaluating the clinical usefulness of a screening test, as likelihood ratios are not affected by the prevalence of a disease. ${ }^{13}$ However, to the best of our knowledge, likelihood ratios have not been used to evaluate prostate specific antigen as a screening test for prostate cancer. The usefulness of a screening test is determined by how well it predicts disease, and this can be evaluated by using likelihood ratios while adapting for various existing risk factors for disease. Hence, a risk estimate can be estimated on the basis of a combination of risk factors, rather than using a single cut-off value. ${ }^{13} \mathrm{~A}$ positive likelihood ratio above 10 for a diagnostic test is considered to be strong evidence to "rule in" disease, whereas a negative likelihood ratio below 0.1 is considered sufficient evidence to "rule out" disease. ${ }^{14}$ In our data, no single cut-off value for prostate specific antigen resulted in positive and negative likelihood ratios close to these values. However, a cut-off of $1.0 \mathrm{ng} / \mathrm{ml}$ resulted in a negative likelihood ratio of 0.08 , and only six $(1.2 \%)$ men diagnosed as having high risk cancer had pre-diagnostic prostate specific antigen concentrations below $1.0 \mathrm{ng} / \mathrm{ml}$, suggesting that this cut-off may

\section{WHAT IS ALREADY KNOWN ON THIS TOPIC}

The performance of prostate specific antigen testing for early detection of prostate cancer is good overall, as shown in both longitudinal and cross sectional studies

The European Randomized Study of Screening for Prostate Cancer (ERSPC) found a 20\% decrease in the rate of death from prostate cancer in the screening arm

However, overdiagnosis and overtreatment are a concern when using serum concentrations of prostate specific antigen to screen for prostate cancer

\section{WHAT THIS STUDY ADDS}

No cut-off value for prostate specific antigen attained the likelihood ratios formally required for a screening test

However, concentrations below $1.0 \mathrm{ng} / \mathrm{ml}$ virtually ruled out a subsequent diagnosis of prostate cancer

These data, in combination with data from the recent screening trials, indicate that further biomarkers are needed before population based screening for prostate cancer should be introduced be useful in identifying men with very low risk of prostate cancer. This result is in accordance with data from a screening study in Gothenburg, Sweden, in which no man with a prostate specific antigen concentration below $1.0 \mathrm{ng} / \mathrm{ml}$ was diagnosed as having prostate cancer during three years of follow-up. ${ }^{26}$

\section{Strengths and limitations}

Baseline characteristics of a study population influence estimates of validity. In particular, characteristics of tumours affect estimates of sensitivity, and one advantage of our study was that the case mix mirrored that of the source population, a property strengthening the external validity of our study. ${ }^{24}$ The standardised incidence rate ratio for prostate cancer in the Västerbotten Intervention Project cohort was 1.05 (95\% confidence interval 0.96 to 1.16 ) compared with the source population up to 2002. Another advantage of our study was the relatively low frequency of testing for prostate specific antigen. Notably, our dataset represented a "best case scenario," in that the likelihood ratios in populations with a higher uptake of testing for prostate specific antigen and consequently a larger proportion of low risk tumours will be substantially less advantageous than we observed. ${ }^{15}$

Characteristics of controls affect estimates of specificity, and the median concentration and distribution of prostate specific antigen concentrations in our controls were very similar to those in the European Randomized Study of Screening for Prostate Cancer. ${ }^{8}$ The specificity estimates obtained in our study were also similar to those obtained in other investigations with similar, and different, study designs. ${ }^{151920}$ Hence, the results of this study can be extrapolated to other white European populations in which no widespread screening with prostate specific antigen tests is ongoing. However, the lack of long follow-up is a limitation of our study.

\section{Conclusions}

Although prostate specific antigen has a relatively high validity for prediction of subsequent prostate cancer, this longitudinal study shows that no cut-off value for 
prostate specific antigen attains the likelihood ratios formally required for a screening test. However, prostate specific antigen concentrations below $1.0 \mathrm{ng} / \mathrm{ml}$ virtually ruled out a diagnosis of prostate cancer during follow-up, and higher prostate specific antigen concentrations expressed a continuum of prostate cancer risk. Taken together, our study and the recent findings from screening trials strongly indicate that in addition to serum concentrations of prostate specific antigen, further biomarkers are needed before population based screening for prostate cancer can be recommended.

We thank all participants in the Northern Sweden Health and Disease Cohort project, and we thank Åsa Ågren, Charlotte Ingri, and Björn Tavelin for their assistance in project coordination and data management. Contributors: PS, MJ, and GH contributed to study conception and design. $\mathrm{PS}, \mathrm{BH}, \mathrm{MJ}, \mathrm{U}-\mathrm{HS}$, and $\mathrm{AB}$ contributed to analysis and interpretation of the data. U-HS did the biochemical analysis. AB was responsible for revision of core biopsies. BH, MJ, and PS contributed to drafting of the article. All authors critically revised the article for important intellectual content and gave final approval. GH provided the study participants. MJ provided statistical expertise. PS obtained funding. BH, MJ, and PS are the guarantors

Funding: This study was supported by grants from the Swedish Cancer Foundation and the Lion's Cancer Research Foundation at Umeå University. The funding source had no role in the study design; collection, analysis, and interpretation of data; in the writing of the report; and in the decision to submit the article for publication. The researchers were all independent from the funding source.

Conflicts of interest: None declared.

Ethical approval: The research ethical committee at Umeå University Hospital approved of the study.

1 Ross KS, Carter HB, Pearson JD, Guess HA. Comparative efficiency of prostate-specific antigen screening strategies for prostate cancer detection. JAMA 2000;284:1399-405.

2 Yao SL, Lu-Yao G. Interval after prostate specific antigen testing and subsequent risk of incurable prostate cancer. J Urol 2001;166:861-5.

3 Smith RA, Cokkinides V, Brawley OW. Cancer screening in the United States, 2008: a review of current American Cancer Society guidelines and cancer screening issues. CA Cancer / Clin 2008:58:161-79.

4 Lieberman R. Evidence-based medical perspectives: the evolving role of PSA for early detection, monitoring of treatment response, and as a surrogate end point of efficacy for interventions in men with different clinical risk states for the prevention and progression of prostate cancer. Am J Ther 2004;11:501-6.

5 Stenman UH, Abrahamsson PA, Aus G, Lilja H, Bangma C, Hamdy FC, et al. Prognostic value of serum markers for prostate cancer. Scand Urol Nephrol Suppl 2005;216:64-81.

6 Kwiatkowski M, Stieber P, Huber AR, Recker F. Selective application of tumor markers PSA. Ther Umsch 2008;65:493-501.

7 Schröder FH, Hugosson J, Roobol MJ, Tammela TL, Ciatto S, Nelen V, et al. Screening and prostate-cancer mortality in a randomized European study. N Engl / Med 2009;360:1320-8.

8 De Koning HJ, Auvinen A, Berenguer Sanches A, Calais da Silva F, Ciatto S, Denis L, et al. Large-scale randomized prostate cancer screening trials: program performances in the European randomized screening for prostate cancer trial and the prostate, lung, colorectal and ovary cancer trial. Int J Cancer 2002;97:237-44.

9 Hugosson J, Aus G, Lilja H, Lodding P, Pihl CG. Results of a randomized, population-based study of biennial screening using serum prostate-specific antigen measurement to detect prostate carcinoma. Cancer 2004;100:1397-405.

10 Maattanen L, Hakama M, Tammela TL, Ruutu M, Ala-Opas M, Juusela $\mathrm{H}$, et al. Specificity of serum prostate-specific antigen determination in the Finnish prostate cancer screening trial. $\mathrm{Br}$ J Cancer 2007;96:56-60

11 Makinen T, Tammela TL, Hakama M, Stenman UH, Rannikko S, Aro et al. Prostate cancer screening within a prostate specific antigen range of 3 to $3.9 \mathrm{ng} / \mathrm{ml}$ : a comparison of digital rectal examination and free prostate specific antigen as supplemental screening tests.J Urol 2001;166:1339-42.

12 Barry MJ. Prostate-specific-antigen testing for early diagnosis of prostate cancer. N Engl J Med 2001;344:1373-7.

13 Deeks JJ, Altman DG. Diagnostic tests 4: likelihood ratios. BMJ 2004;329:168-9.

14 Jaeschke R, Guyatt G, Lijmer J. Diagnostic tests. In: Guyatt G, Rennie D, eds. Users' guides to the medical literature. Chicago: A MA Press, 2002:121-40.

15 Thompson IM, Ankerst DP, Chi C, Lucia MS, Goodman PJ, Crowley JJ, et al. Operating characteristics of prostate-specific antigen in men with an initial PSA level of $3.0 \mathrm{ng} / \mathrm{ml}$ or lower. IAMA 2005;294:66-70.

16 Stenman UH, Hakama M, Knekt P, Aromaa A, Teppo L, Leinonen J. Serum concentrations of prostate specific antigen and its complex with alpha 1-antichymotrypsin before diagnosis of prostate cancer. Lancet 1994;344:1594-8.

17 Parkes C, Wald NJ, Murphy P, George L, Watt HC, Kirby R, et al. Prospective observational study to assess value of prostate specific antigen as screening test for prostate cancer. BM/ 1995;311:1340-3.

$18 \mathrm{Gann}$ PH, Hennekens CH, Stampfer MJ. A prospective evaluation of plasma prostate-specific antigen for detection of prostatic cancer. IAMA 1995;273:289-94.

19 Hakama M, Stenman UH, Aromaa A, Leinonen J, Hakulinen T, Knekt P. Validity of the prostate specific antigen test for prostate cancer screening: followup study with a bank of 21,000 sera in Finland. J Urol 2001:166:2189-91.

20 Gann PH, Ma J, Catalona WJ, Stampfer MJ. Strategies combining total and percent free prostate specific antigen for detecting prostate cancer: a prospective evaluation. J Urol 2002;167:2427-34.

21 Lilja H, Ulmert D, Bjork T, Becker C, Serio AM, Nilsson JA, et al. Longterm prediction of prostate cancer up to 25 years before diagnosis of prostate cancer using prostate kallikreins measured at age 44 to 50 years. I Clin Oncol 2007:25:431-6.

22 Stattin P, Rinaldi S, Biessy C, Stenman UH, Hallmans G, Kaaks R. High levels of circulating insulin-like growth factor-l increase prostate cancer risk: a prospective study in a population-based nonscreened cohort. / Clin Oncol 2004:22:3104-12.

23 Weinehall L, Hallgren CG, Westman G, Janlert U, Wall S. Reduction of selection bias in primary prevention of cardiovascular disease through involvement of primary health care. Scand J Prim Health Care 1998;16:171-6

24 Adolfsson J, Garmo H, Varenhorst E, Ahlgren G, Ahlstrand C, Andren 0 , et al. Clinical characteristics and primary treatment of prostate cancer in Sweden between 1996 and 2005. Scand I Uro Nephrol 2007;41:456-77.

25 Vessella RL, Noteboom J, Lange PH. Evaluation of the Abbott IMx automated immunoassay of prostate-specific antigen. Clin Chem 1992;38:2044-54

26 Aus G, Damber JE, Khatami A, Lilja H, Stranne J, Hugosson J. Individualized screening interval for prostate cancer based on prostate-specific antigen level: results of a prospective, randomized, population-based study. Arch Intern Med 2005;165:1857-61.

27 Fagan T). Nomogram for Bayes theorem [letter]. N Engl] Med 1975;293:257.

28 Andriole GL, Grubb RL, Buys SS, Chia D, Church TR, Fouad MN, et al. Mortality results from a randomized prostate-cancer screening trial. N Engl / Med 2009;360:1310-9.

29 Pepe MS, Janes H, Longton G, Leisenring W, Newcomb P. Limitation of the odds ratio in gauging the performance of a diagnostic, prognostic, or screening marker. Am J Epidemiol 2004;159:882-90

30 Ware $\mathrm{JH}$. The limitations of risk factors as prognostic tools. N EnglJ Med 2006;355:2615-7.

31 Lilienfeld AM. Some limitations and problems of screening for cancer. Cancer 1974:33:1720-4.

32 Baker SG. The central role of receiver operating characteristic (ROC) curves in evaluating tests for the early detection of cancer. J Natl Cancer Inst 2003;95:511-5.

Accepted: 5 June 2009 